Check for updates

Cite this: RSC Adv., 2019, 9, 11092

Received 8th December 2018

Accepted 25th March 2019

DOI: 10.1039/c8ra10091h

rsc.li/rsc-advances

\section{Immunomodulatory activity of a fructooligosaccharide isolated from burdock roots}

\begin{abstract}
Xiu-juan Zhang, ${ }^{a}$ Shao-fang Liu, ${ }^{b}$ Yan Lu, ${ }^{a}$ Jian-yue Wang ${ }^{a}$ and Kao-shan Chen (D) *ac
A novel burdock fructooligosaccharide (BFO-1) was extracted from fresh burdock roots. In our study, we found that BFO-1 possessed immunoenhancing activity in vitro and in vivo. The proliferation activities of splenocytes were significantly stimulated at a BFO-1 dose of $1000 \mu \mathrm{g} \mathrm{ml}^{-1}(p<0.05)$, peritoneal macrophages showed increased activities of phagocytosis and acid phosphatase and increased production of $\mathrm{NO}$ at a BFO-1 dose of $1000 \mu \mathrm{g} \mathrm{ml}^{-1}(p<0.01)$ in vitro. In normal mice, BFO-1 promoted the activities of peritoneal macrophages at dosages of 250 and $500 \mathrm{mg}$ per $\mathrm{kg}$ per day $(p<0.01)$. Similarly, in immunosuppressed mice, BFO-1 enhanced the activities of peritoneal macrophages at the dosage of $1000 \mathrm{mg}$ per $\mathrm{kg}$ per day $(p<0.05)$. Furthermore, S180 tumor-bearing mice that were preadministered BFO-1 solution showed improved immunological function and suppressed tumor growth. These data indicate that BFO-1 can improve the functioning of the immune system and has the potential to be developed as a dietary supplement and medicinal food.
\end{abstract}

\section{Introduction}

Currently, some common diseases are closely associated with a compromised immune system, which is due to problems of the immune system and nonspecific protection mechanisms being damaged in disease and cancer. For the treatment of immunocompromised patients, immunotherapy has attracted increasing attention. Plant polysaccharides are an important active ingredient in Chinese traditional medicine and have been widely studied for their safety and nontoxic characteristics. A large number of studies have shown that plant polysaccharides enhance the immune functions of the body and are one of the main mechanisms for their medicinal use. Plant polysaccharides not only activate immune cells such as T cells, B cells, macrophages, and NK cells but also promote the production of cytokines such as IL-1, IL-2, tumor necrosis factor and interferon, regulate the formation of antibodies and complement and exert various regulatory effects on the immune system. ${ }^{1-4}$

Burdock (Arctium lappa L.), which is a famous traditional Chinese medicine, has long been cultivated as a popular vegetable in Japan, Korea, Taiwan and has yet to be shown to cause

${ }^{a}$ School of Life Science, Shandong University, Qingdao, 266000, China. E-mail: ksc313@126.com

${ }^{b}$ Shandong Peanut Research Institute Qingdao, Shan Dong, China

'Anhui Provincial Engineering Research Center for Polysaccharide Drugs, Anhui Province Key Laboratory of Active Biological Macromolecules, Drug Research \& Development Center, School of Pharmacy, Wannan Medical College, Wuhu, 241002, China side effects. ${ }^{5}$ Burdock roots contain large amounts of fructooligosaccharides, phenolic compounds and caffeoylquinic acid derivatives; ${ }^{6-8}$ fructooligosaccharides are usually considered to be their main bioactive components. ${ }^{9}$ Some studies have suggested that burdock has a variety of biological properties, such as antioxidant, antiallergic, immunoregulatory or immunostimulatory or immunostimulation ${ }^{10-15}$ and anti-inflammatory activities. ${ }^{16,17}$

Approximately $15 \%$ of angiosperms store carbohydrates in the form of fructooligosaccharides. Fructooligosaccharides, as burdock root's main bioactive components, are a kind of fine functional food material that has been used globally. In addition to being a sugar alcohol, fructooligosaccharide also regulates intestinal flora, ${ }^{18-21}$ lowers blood sugar, ${ }^{22}$ regulates fat metabolism, ${ }^{23}$ promotes the absorption of minerals, increases the number of Peyer's patch, ${ }^{24}$ promotes the production of short chain fatty acids (SCFAs) ${ }^{25}$ and so on.

Our laboratory isolated and purified a homogeneous fructooligosaccharide from fresh burdock roots named BFO-1, which consisted of glucose and fructose, composed of D-fructose and D-glucose in a molar ratio of approximately $12: 1$. BFO- 1 is confirmed to be composed of 12 fructose residues linked by $\mathrm{U}$ $(2 \rightarrow 1)$ glucoside bonds and 1 glucose residue linked by a $\mathrm{T}(1 \rightarrow$ 2) glucoside bond at the end of the linear straight sugar chain. Preliminary experiments confirmed that BFO-1 could promote plant growth and inhibit plant diseases. In addition, BFO-1 induced the growth of Bifidobacterium in vitro, but the immunomodulatory activity of BFO-1 has not been studied. Accordingly, in this study, we investigated the immunomodulatory activity of BFO-1 for the first time. We then investigated the 
effect of BFO-1 on immune cells, normal mice, and immunosuppressed mice treated with cyclophosphamide and S180 tumor-bearing mice. Our results provide insights into the understanding of BFO-1 from burdock roots and may facilitate its application in biomedical fields.

\section{Materials and methods}

\section{Materials}

D301R resin was provided by Nankai University. Sephadex G-50 was purchased from General Electric Healthcare Life Sciences. Fetal bovine serum and RPMI-1640 media were obtained from GIBCO GRL (USA). Lipopolysaccharide (LPS), 3-(4,5dimethylthiazol-2-y1)-2,5-diphenyltetrazoliumbromide (MTT), concanavalin A (ConA) and p-nitrophenyl phosphate (pNPP) were purchased from Sigma-Aldrich Chemical Co. (St. Louis, MO, USA). Sheep red blood cells (SRBCs) were obtained from Solarbio.

\section{Isolation and fractionation of burdock fructooligosaccharide}

The roots of fresh burdock were cut into pieces and immersed in hot water at a solid : liquid ratio of $1: 10$, at a temperature of $70{ }^{\circ} \mathrm{C}$, and an extraction time of $90 \mathrm{~min}$, which was repeated twice. The liquid was concentrated by rotary evaporation at $60{ }^{\circ} \mathrm{C}$ to $1 / 3$ of the original volume and mixed with three volumes of $95 \%$ ethanol for $24 \mathrm{~h}$ at $4{ }^{\circ} \mathrm{C}$. The samples were deproteinized according to the method of Sevage (1938), then decolorized with D301R and freeze-dried to obtain crude burdock fructooligosaccharide. The crude burdock fructooligosaccharide was fractionated by Sephadex G-50 column chromatography $(1.6 \mathrm{~cm} \times 60 \mathrm{~cm})$ and eluted with distilled water with a flow rate of $0.5 \mathrm{ml} \mathrm{min}{ }^{-1}$. The fraction of the major peak was collected, lyophilized and pure burdock fructooligosaccharide named BFO was obtained.

\section{Removal of bacterial endotoxins from burdock fructooligosaccha-ride}

DEAE-cellulose column chromatography was used to remove bacterial endotoxins. The DEAE-cellulose was weighed, and three times the amount of water was added to dissolve the DEAE-cellulose, which was stabilized by 2-3 times the volume of the column after the alkali-acid-alkali treatment. BFO was eluted with distilled water at a flow rate of $1 \mathrm{ml} \mathrm{min}^{-1}$, and the concentrated liquor was lyophilized and named BFO-1. The endotoxin level was measured at the end point by the chromogenic reagent TAL.

\section{Animal}

Kunming mice $(20 \pm 2 \mathrm{~g}$, female) were obtained from the Animal Centre of Shandong University. Mice were kept in a room under standard housing conditions (12 h light/12 h dark, $25 \pm 1{ }^{\circ} \mathrm{C}$ with $55 \pm 5 \%$ relative humidity). All experiments were performed in compliance with the relevant laws and approved by the Ethics Committee of Shandong University with the approval/protocol number SYDWLL-2018-12, which is according to the regulations for the Administration of Affairs Concerning Experimental Animals of China.

\section{The proliferation of splenocytes}

Kunming mice were sacrificed by cervical dislocation, and the spleens were aseptically acquired. The single-cell suspensions were obtained by pressing the suspension with a syringe core and filtering through a 200-mesh steel sieve. The erythrocytes were removed by the hypotonic method and then washed three times with phosphate buffered saline (PBS) and centrifuged at $1000 \mathrm{rpm}$ for $5 \mathrm{~min}$. Finally, splenocytes were suspended at $1 \times$ $10^{6} \mathrm{ml}^{-1}$ in RPMI 1640 medium supplemented with $10 \%$ fetal bovine serum. The cells were seeded in 96-well plates with different concentrations of BFO-1 or ConA $\left(5 \mu \mathrm{g} \mathrm{ml}^{-1}\right)$, followed by incubation for $72 \mathrm{~h}$ at $37{ }^{\circ} \mathrm{C}$ with $5 \% \mathrm{CO}_{2}$ in a humidified incubator. A $5 \mathrm{mg} \mathrm{ml}^{-1}$ MTT solution $(10 \mu \mathrm{l})$ was added to each well before the end of the culture for $4 \mathrm{~h}$ and incubated continuously for $4 \mathrm{~h}$. The supernatant was removed carefully, and DMSO $(150 \mu \mathrm{l})$ was added to each well until the blue-purple crystallization of formazan was completely dissolved. Then, the absorbance was measured with a microplate reader at $570 \mathrm{~nm}$.

\section{The production of NO in peritoneal macrophages}

Mice were injected with $1 \mathrm{ml}$ of aseptic 3\% starch broth in the abdominal cavity for 3 days. Five millilitres of cold PBS solution was injected into the abdominal cavity, and the abdomen was gently massaged. Then, the peritoneal macrophages were collected and washed twice with PBS. The purified peritoneal macrophages $\left(1 \times 10^{6} \mathrm{ml}^{-1}\right)$ were seeded in 96-well plates and treated with different concentrations of BFO-1 $(0,25,50,100$, $\left.500,1000 \mu \mathrm{g} \mathrm{ml}{ }^{-1}\right)$ or LPS $\left(1 \mu \mathrm{g} \mathrm{ml}{ }^{-1}\right)$ for $24 \mathrm{~h}$. Then, the supernatant $(50 \mu \mathrm{l})$ was placed in another 96-well cell culture plate, and Griess reagent $(50 \mu \mathrm{l})$ was added, gently mixed and settled at room temperature for $10 \mathrm{~min}$. Then, the absorbance of each well was measured at $490 \mathrm{~nm}$ with a microplate reader.

\section{The determination of acid phosphatase activity in macrophage}

Purified peritoneal macrophages $\left(1 \times 10^{6} \mathrm{ml}^{-1}\right)$ were seeded in 96-well plates and treated with different concentrations of BFO$1\left(0,25,50,100,500,1000 \mu \mathrm{g} \mathrm{ml}^{-1}\right)$ or LPS $\left(1 \mu \mathrm{g} \mathrm{ml} \mathrm{m}^{-1}\right)$ for $24 \mathrm{~h}$. The supernatant was removed, and $100 \mu \mathrm{l}$ of pNPP was added to every well. Then, the cells were sequentially cultivated for $30 \mathrm{~min}$, and $10 \mu \mathrm{l}$ of $\mathrm{NaOH}\left(1.0 \mathrm{~mol} \mathrm{l}^{-1}\right)$ was added to terminate the reaction. The absorbance of each well was measured by a microplate reader at $405 \mathrm{~nm}$.

\section{Phagocytic activity of peritoneal macrophages}

The purified peritoneal macrophages were incubated alone for $24 \mathrm{~h}$. Subsequently, the supernatant was discarded, and $100 \mu \mathrm{l}$ of $0.1 \%$ neutral red dissolved in normal saline was added. Then, the cells were sequentially cultivated for $20 \mathrm{~min}$, and $200 \mu \mathrm{l}$ of cell lysis buffer composed of equal volumes of absolute ethanol and acetic acid was added to every well. The absorbance was measured at $490 \mathrm{~nm}$ under a microplate reader. 


\section{B cell-mediated hemolysis reaction}

Mice were injected with $20 \% \operatorname{SRBC}(0.2 \mathrm{ml})$ and sacrificed on day 8 , and splenocytes were prepared according to the methods described above. One milliliter of spleen cell suspension $(1 \times$ $10^{7} \mathrm{ml}^{-1}$ ), $0.5 \mathrm{ml}$ of $0.2 \%$ SRBC and $0.5 \mathrm{ml}$ of $1: 10$ guinea pig complement was mixed and incubated for $60 \mathrm{~min}$ at $37^{\circ} \mathrm{C}$; finally, the reaction was stopped in an ice bath. The cell suspension was then centrifuged (3000 rpm for $5 \mathrm{~min}$ ), and the absorbance of the supernatant was measured by a microplate reader at $413 \mathrm{~nm}$.

\section{The determination of serum hemolysin}

Mice were injected with $20 \%$ SRBC $(0.2 \mathrm{ml})$ and sacrificed on day 8 . The serum was separated and diluted with physiological saline at a ratio of $1: 100$. One millilitre of serum was mixed with $5 \%$ SRBC $(0.5 \mathrm{ml})$ and $1: 10$ guinea pig complement (0.5 $\mathrm{ml}$ ). After a $60 \mathrm{~min}$ incubation at $37{ }^{\circ} \mathrm{C}$, the reaction was terminated in an ice bath and the mixture was centrifuged at $3000 \mathrm{rpm}$ for $5 \mathrm{~min}$. The absorbance was measured at $540 \mathrm{~nm}$ using a microplate reader.

\section{Experimental design for normal mice}

The mice were randomly divided into five groups ( $n=6$ /group): the control group and the four experimental groups. After acclimation for 1 week, in the experimental groups, the mice were orally administered BFO-1 (100, 250, 500, and $1000 \mathrm{mg}$ $\mathrm{kg}^{-1}$ ) every day for a week, and the control group was administered the equivalent volume of saline. After 1 week, all groups were euthanized to prepare splenic cells and peritoneal macrophages as described above. Then, the proliferation of splenocytes, the phagocytic activity of peritoneal macrophages, the production of NO and the acid phosphatase activity, B cellmediated hemolysis reaction and the production of serum hemolysin were measured as described above.

\section{Experimental design for cyclophosphamide-treated immunosuppressed mice}

The Kunming mice were randomly divided into five groups ( $n=$ 6/group). In the experimental groups, the mice were injected with $75 \mathrm{mg} \mathrm{kg}^{-1} \mathrm{~d}^{-1}$ cyclophosphamide (CY) for 3 days, and the control group was injected with the equivalent volume of saline. Then, the experimental groups were treated with normal saline and different concentrations of BFO-1 (250, 500, $\left.1000 \mathrm{mg} \mathrm{kg}^{-1}\right)$ by lavage every day for 7 days. Then, the proliferation of splenocytes, the phagocytic activity of peritoneal macrophages, the production of NO and the acid phosphatase activity, B cell mediated hemolysis reaction and the production of serum hemolysin were measured as described above.

\section{Experimental design for S180 tumor-bearing mice}

The Kunming mice were randomly divided into five groups $(n=$ 8/group): the control group and the four experimental group. In the experimental groups, the mice were orally administered BFO-1 (250, 500, and $\left.1000 \mathrm{mg} \mathrm{kg}^{-1}\right)$ every day for a week and the control group was administered the equivalent volume of saline. The five groups of mice were subcutaneously inoculated with $0.2 \mathrm{ml}$ of $\mathrm{S} 180$ cell suspension $\left(1 \times 10^{7} \mathrm{ml}^{-1}\right)$ in the right upper limb on day 8 , and then BFO-1 and saline were administered on the other 9 days. The mice were sacrificed, and the tumor tissue was detached and weighed. The tumor inhibition rate was calculated according to the following formula:

Tumor inhibition rate $(\%)=\left(W_{\text {control }}-W_{\text {treated }}\right) / W_{\text {control }} \times$ $100 \%$, where $W_{\text {treated }}$ and $W_{\text {control }}$ were the average tumor weights of the treated and control groups, respectively. The phagocytic activity of the peritoneal macrophages and the production of NO were measured as described above.

\section{Statistical analysis}

All data are presented as the mean \pm SD. The statistical calculations were performed using the Statistical Package for Social Sciences version 12.0 (SPSS Inc., Chicago, IL, USA). Significant values were evaluated by one-way ANOVA, and $p$-values of less than 0.05 were considered statistically significant.

\section{Results}

\section{Isolation and removal of bacterial endotoxin from BFO}

Endotoxin is the source of pollution of most biomaterials, and its presence has clouded the results of biological and drug tests and caused many production difficulties. ${ }^{26}$ The removal of endotoxin is a difficult problem, due to its high thermal stability and relatively large molecular weight; the stability and recovery rate of biological macromolecules should also be considered. ${ }^{27}$

BFO-1 was separated by a DEAE-cellulose column to obtain loose white lumps. DEAE cellulose is one of the most commonly used methods in the separation and purification of sugars. Results have shown that the method of removing bacterial endotoxin by DEAE cellulose is low cost, effective, has a high recovery rate and is also a suitable method for removing BFO-1 contaminating endotoxin. This study selected an appropriate method to determine the content of endotoxin. After treatment, the endotoxin measurement changed from $1.6702 \mathrm{EU} \mathrm{ml}^{-1}$ to $0.1065 \mathrm{EU} \mathrm{ml} \mathrm{ml}^{-1}$. The endotoxin content was reduced by approximately 25 times, and the BFO- 1 can therefore be used for further experiments. The removal of bacterial endotoxin by DEAE cellulose is effective and feasible.

\section{The effect of BFO on the proliferation of splenocytes in vitro}

In this study, the proliferation activity of splenic cells was determined by MTT assay. As shown in Fig. 1, compared with the control, BFO-1 effectively stimulated splenic cell proliferation in a dose-dependent manner and reached maximum proliferation at $1000 \mu \mathrm{g} \mathrm{ml}{ }^{-1}$. This result indicates that BFO-1 can stimulate lymphocyte proliferation within a certain concentration range.

\section{The effect of BFO-1 on peritoneal macrophages in vitro}

The acid phosphatase activity and the production of NO in peritoneal macrophages could not be enhanced by BFO-1 stimulation alone in vitro (data not shown), but LPS alone can stimulate peritoneal macrophages to produce NO. In this study, 


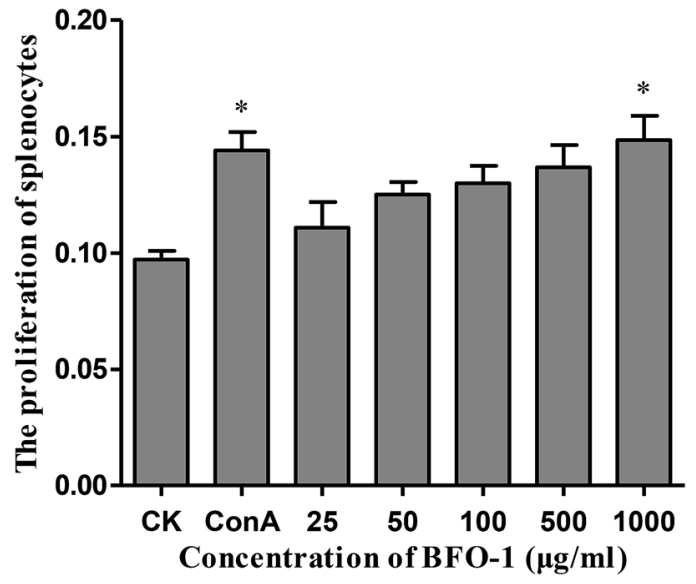

Fig. 1 Effect of BFO-1 on the proliferation activity of spleen cells in vitro. Supernatants of ConA or BFO-1 treated spleen cells were collected, and the OD value was measured with a microplate reader at $570 \mathrm{~nm}$. Data are presented as the means \pm SD of six independent experiments. Significant differences from the control group are indicated by $* p<0.05, * * p<0.01$.

the synergistic effect of BFO-1 and LPS on the production of NO in macrophages was investigated. The results showed that NO was significantly increased after combined stimulation with BFO-1 and LPS. When the concentration of BFO-1 was 25-100 $\mu \mathrm{g} \mathrm{ml}{ }^{-1}$, the NO production tended to decrease as the concentration increased. When the concentration of BFO-1 was 500$1000 \mu \mathrm{g} \mathrm{ml}^{-1}$ in the test group, the production of NO was higher than in the control and LPS groups with increasing concentrations (Fig. 2A). It is possible that the mechanism of NO production stimulated by BFO-1 is different. How BFO-1 and LPS synergistically impact the production of NO is unclear. BFO-1 could enhance the activity of acid phosphatase in peritoneal macrophages. As the concentration increased, the activity of acid phosphatase also increased; at the concentration of $1000 \mu \mathrm{g} \mathrm{ml} \mathrm{m}^{-1}$, the acid phosphatase activity was dramatically higher than the control group $(p<0.05)$. The results are shown in Fig. 2B.

\section{The immunostimulatory effects of BFO on normal mice}

To further evaluate the immunostimulatory effect of BFO-1 on normal mice, BFO-1 was orally administered at dosages of 100 , 250, 500 and $1000 \mathrm{mg}$ per $\mathrm{kg}$ per day to normal mice for 7 days. The production of $\mathrm{NO}$, the phosphatase activity and the phagocytic activity of peritoneal macrophages from normal mice are shown in Fig. 3. At concentrations of 250 and $500 \mathrm{mg}$ per kg per day, the acid phosphatase activity, NO production and phagocytic activity of the BFO-1 groups were dramatically higher than those of the control group $(p<0.01)$. However, at $1000 \mathrm{mg}$ per $\mathrm{kg}$ per day, the acid phosphatase activity and NO production of the BFO-1 groups were decreased, probably because the concentration of BFO-1 was too high. BFO-1 did not show toxic effects despite the high BFO-1 concentration. BFO-1 increased the proportion of activated macrophages at concentrations of 100-1000 $\mathrm{mg}$ per $\mathrm{kg}$ per day.

However, intragastric treatment of normal mice with BFO-1 for 7 days did not change the proliferation of splenic cells, the B cell-mediated hemolysis reaction or the determination of serum hemolysin compared with the control group mice. The phagocytic activity of macrophages, the production of cytokines, the ability of splenic cells to secrete antibodies, and the proliferation of splenic lymphocytes reflect the cellular and humoral immune functions of the immune system.

\section{The immunostimulatory effects of BFO-1 in immunosuppressed mice}

Proliferation of splenocytes. The splenocyte proliferation results are shown in Fig. 4. The proliferation activity of splenic cells was increased in the BFO-1 groups relative to the model group. Compared with the model group, splenic cells proliferation was stimulated in the BFO-1 treatment groups in a dose-
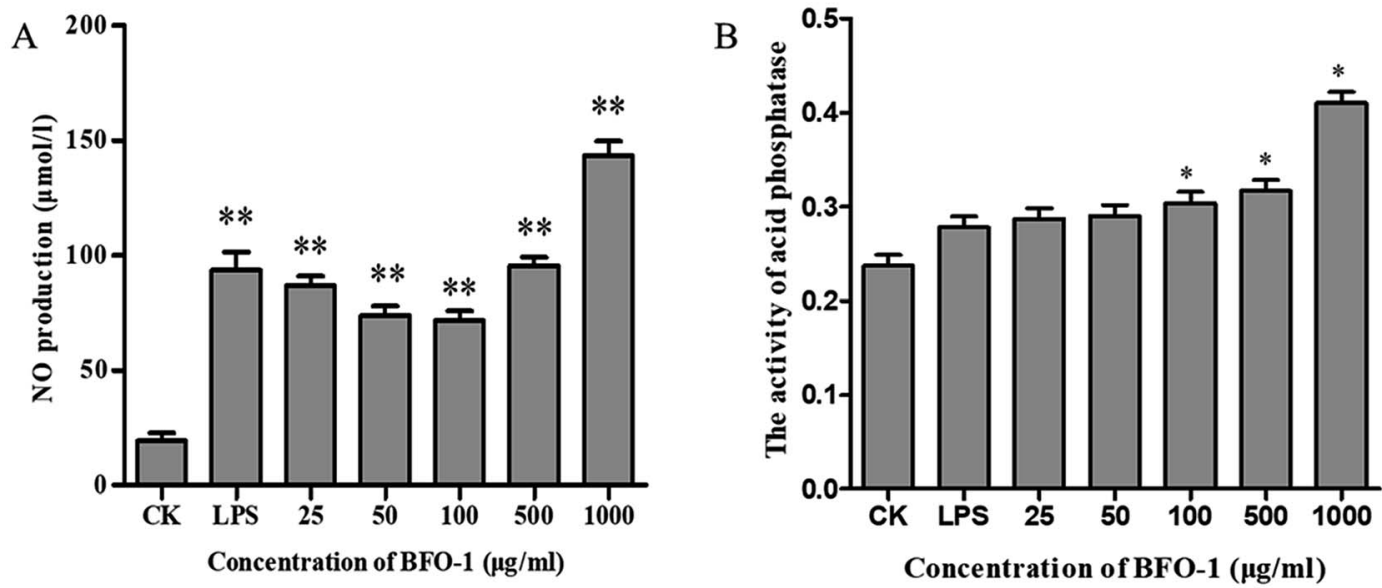

Fig. 2 The effects of BFO-1 on peritoneal macrophages in vitro. (A) Effects of BFO-1 on the production of NO in macrophages. (B) Effect of BFO1 on the activity of acid phosphatase in macrophages. Macrophages were treated with the indicated concentrations of BFO or LPS $\left(1 \mu \mathrm{g} \mathrm{ml}{ }^{-1}\right)$ for $24 \mathrm{~h}$. The results are expressed as the mean values \pm SD ( $n=6,{ }^{*} p \leq 0.05$ versus control group). 

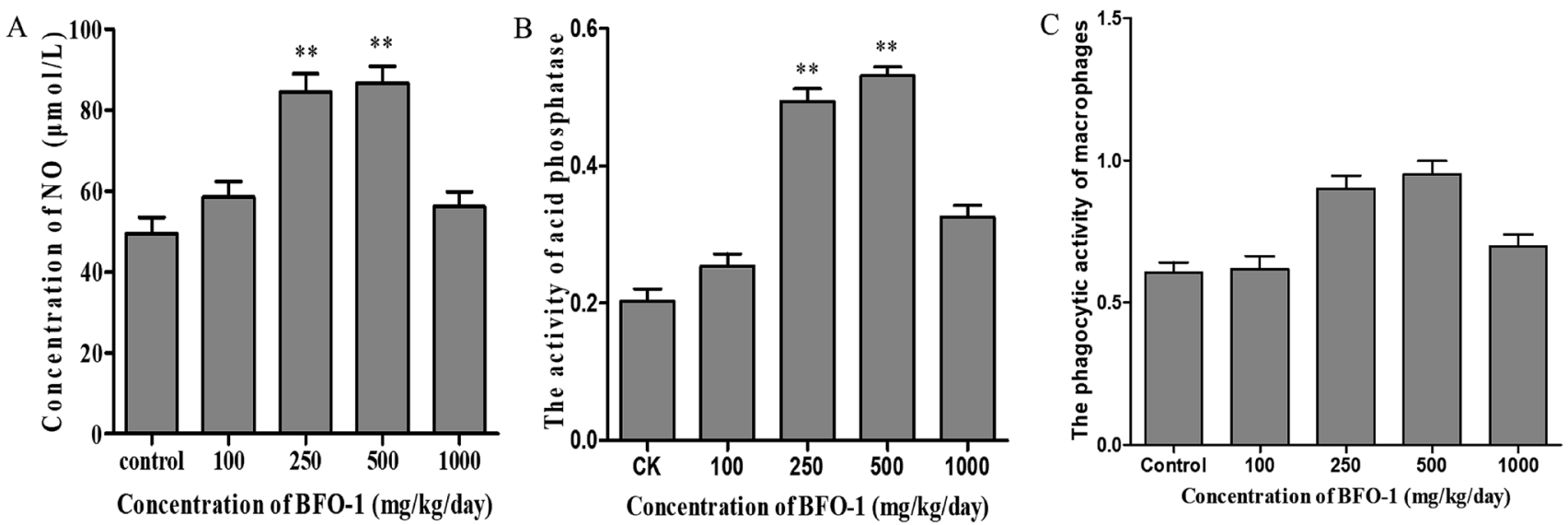

Fig. 3 Effect of BFO-1 on peritoneal macrophages from normal mice. (A) Effect of BFO-1 on the production of NO in macrophages. (B) Effect of BFO-1 on the activity of acid phosphatase. (C) Effect of BFO-1 on the phagocytic activity of macrophages. The mice were intragastrically pretreated with the indicated concentrations of BFO- 1 for 7 days. The results are expressed as the mean values \pm SD ( $n=6, * p \leq 0.05$ versus control group).

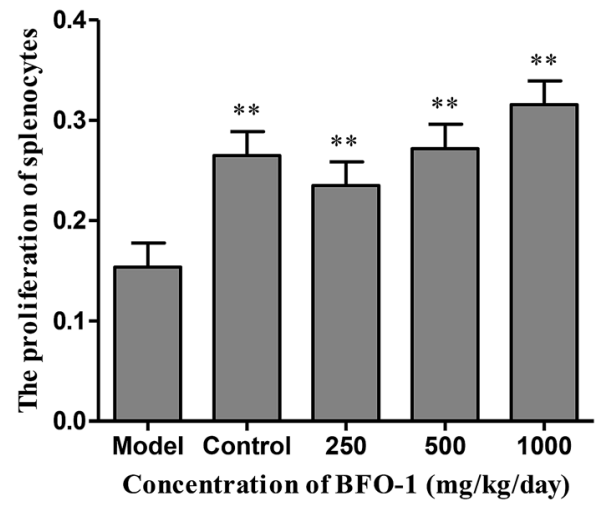

Fig. 4 Effect of BFO-1 on the proliferation of splenocytes in immunosuppressed mice. The results are expressed as the mean values \pm $\mathrm{SD}\left(n=6,{ }^{*} p \leq 0.05\right.$ versus model group).

dependent manner and proliferation reached peaked at $1000 \mathrm{mg}$ per kg per day.

Acid phosphatase activity. The acid phosphatase activity in the BFO-1 treated group at 500 and $1000 \mathrm{mg} \mathrm{kg}^{-1}$ was significantly higher than that in the model group ( $p<0.01$ ) (Fig. 5A). This result suggests that BFO-1 could improve the activity of acid phosphatase to enhance the function of macrophages.

Phosphatase activity. BFO-1 was orally administered at dosages of 250, 500 and $1000 \mathrm{mg}$ per $\mathrm{kg}$ per day, and the phosphatase activity in peritoneal macrophages of immunosuppressed mice was improved. At $1000 \mathrm{mg} \mathrm{kg}^{-1}$, the phosphatase activity was dramatically higher than that of the control group $(p<0.01)$ (Fig. 5B).

The production of serum hemolysin. To evaluate the immunoregulatory effects of BFO-1 in cyclophosphamide induced immunosuppressed mice, the production of serum hemolysin was measured by a microplate reader at $540 \mathrm{~nm}$ (Table 1). At BFO-1 concentration of $1000 \mathrm{mg} \mathrm{kg} \mathrm{kg}^{-1}$, the production of serum hemolysin was dramatically higher than that of the control group $(p<0.05)$. This result suggests that BFO increased the production of serum hemolysin in immunosuppressed mice.

B cell mediated hemolytic activity. To evaluate the immunoregulatory effects of BFO-1 on cyclophosphamide-induced immunosuppression, B cell-mediated hemolytic activity was measured by a microplate reader at $413 \mathrm{~nm}$ (Table 1). The BFO-1 groups had significantly higher hemolytic activity than the model group $(p<0.01)$. This result suggests that BFO-1 improves $\mathrm{B}$ cell mediated hemolytic activity in immunosuppressed mice.

\section{The effect of intragastric pretreatment with BFO-1 on the S180 mice}

The macrophage activation induced by BFO-1 in vitro prompted us to evaluate the anti-tumor and immunomodulatory properties in vivo. We established a subcutaneous S180 tumor-bearing model in Kunming mice to evaluate the immunoregulatory effect of BFO-1.

Tumor inhibition. After intragastric pretreatment with BFO1, the tumor growth of S180-bearing mice was significantly inhibited compared with the tumors from control group (Table 2 ). The tumor inhibition rate in the treatment groups (250 and $500 \mathrm{mg}$ per kg per day) was approximately $25 \%$, while the high dosage group (1000 $\mathrm{mg}$ per $\mathrm{kg}$ per day) reached an inhibition rate of $44 \%$. This result indicates that BFO-1 has preventive effect on the occurrence of tumors. Currently, many studies in the anticancer field are devoted to finding materials with immunoregulatory and antitumor effects from natural biological materials, because traditional chemotherapies kill tumor cells and have a toxic effect on normal cells. ${ }^{28}$ Therefore, ideal antitumor drugs should have tumor suppression function, be harmless to the host or cause limited damage and specifically regulate immune cells to kill tumor cells.

Macrophage phagocytic. Intragastric pretreatment with BFO1 can enhance phosphatase activity and the production of NO in 

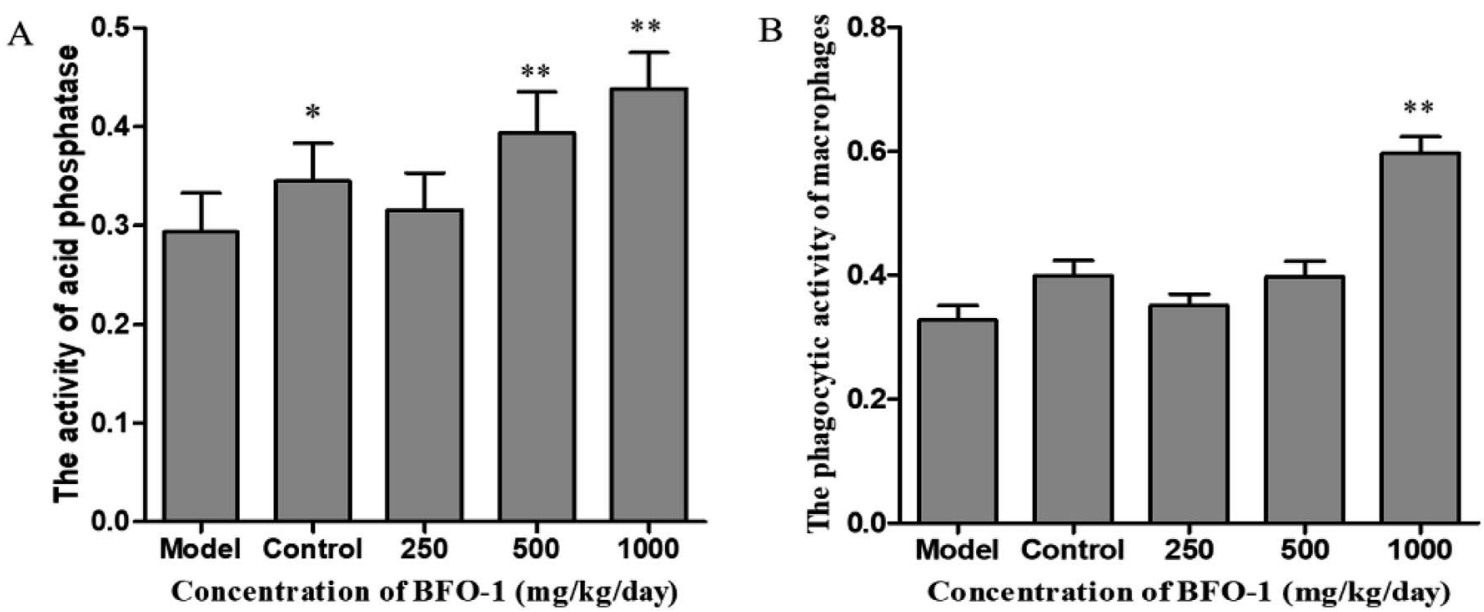

Fig. 5 Effect of BFO-1 on peritoneal macrophages in immunosuppressed mice. (A) Effect of BFO-1 on acid phosphatase activity. (B) Effect of BFO-1 on the phosphatase activity. The results are expressed as the mean values $\pm \operatorname{SD}(n=6, * p<0.05$ versus model group).

macrophages. Compared with the control group of tumorbearing mice, the BFO-1 groups $(250,500$ and $1000 \mathrm{mg}$ per $\mathrm{kg}$ per day) had improved macrophage phagocytic activity and an increased amount of NO (Fig. 6). This result suggests that the intragastric pretreatment effect of BFO-1 has a significant antitumor effect, which may be related to the recovery of immune function in S180 tumor-bearing mice. The immunodeficiency of tumor-bearing mice is closely related to the occurrence and development of tumors. ${ }^{29}$ The results of this study confirmed that BFO-1 can improve the function of macrophages in tumor-bearing mice and exert a positive immunoregulation effect. Therefore, BFO-1 has good application potential in tumor prevention.

\section{Discussion}

In our previous study, we found that BFO-1 is linear inulin-type fructooligosaccharides and acts as prebiotic that passes undigested through the upper part of the gastrointestinal tract. Inulin and fructooligosaccharides are partially hydrolyzed by gut microbes, may either bind to the intestinal epithelium and exert immune reactions locally and/or be absorbed into the bloodstream where they can potentially exert systemic effect. ${ }^{30}$ The current data indicate that BFO-1 enhanced immune function by affecting the activities of lymphocytes and peritoneal macrophages. The activities of splenocytes and peritoneal
Table 2 Effects of BFO-1 pretreatment on tumor weight in S180 tumor-bearing mice $(n=8)^{a}$

\begin{tabular}{lll}
\hline Treatment & $\begin{array}{l}\text { Concentration } \\
\left(\mathrm{mg} \mathrm{kg}^{-1}\right)\end{array}$ & $\begin{array}{l}\text { Tumor inhibition } \\
\text { rate }(\%)\end{array}$ \\
\hline Control & \\
BFO & 250 & 24.26 \\
& 500 & 25.53 \\
& 1000 & 44.14 \\
& \\
& \\
& \\
control stimulation: ${ }^{*} p<0.05,{ }^{* *} p<0.01$. &
\end{tabular}

macrophages were stimulated in vitro (at the dose of $1000 \mu \mathrm{g}$ $\mathrm{ml}^{-1}$ ) and in immunosuppressed mice (at the dosage of $1000 \mathrm{mg}$ per $\mathrm{kg}$ per day). The activities of peritoneal macrophages were significantly stimulated at dosages of 250 and $500 \mathrm{mg}$ per $\mathrm{kg}$ per day in normal mice. Tumor growth was inhibited, and peritoneal macrophages were significantly stimulated at dosages of 250,500 and $1000 \mathrm{mg}$ per $\mathrm{kg}^{-1}$ per day in S180 tumor-bearing mice. In general, BFO-1 can improve immunological function, but the optimal dose for functioning in different models is different.

It is well established that functional foods may exert their beneficial effects on health promotion through cell-to-cell communication networks. ${ }^{31}$ In these communication

Table 1 Effect of BFO-1 on the level of serum hemolysin and B cell mediated hemolytic activity in immunosuppressed mice ${ }^{a}$

\begin{tabular}{|c|c|c|c|}
\hline Groups & Concentration (mg per kg per day) & Serum hemolysin $A_{540}$ & Hemolytic activity $\mathrm{A}_{413}$ \\
\hline Model & & $0.0182 \pm 0.0112$ & $0.1548 \pm 0.0513$ \\
\hline Normal control & & $1.3720 \pm 0.2416$ & $0.7358 \pm 0.0316^{* *}$ \\
\hline \multirow[t]{3}{*}{$\mathrm{BFO}$} & 250 & $0.0891 \pm 10.2416$ & $0.4009 \pm 0.0372 * *$ \\
\hline & 500 & $0.2307 \pm 0.1846$ & $0.4986 \pm 0.0592 * *$ \\
\hline & 1000 & $0.3340 \pm 0.2760^{*}$ & $0.6353 \pm 0.0319 * *$ \\
\hline
\end{tabular}

${ }^{a}$ Date are expressed as the mean $\pm \mathrm{SD}$. Significantly different from the control stimulated: ${ }^{*} p<0.05,{ }^{* *} p<0.01$. 
networks, the immune system plays an important role in the body by protecting the organism from infectious disease and tumors. The immune system is mainly composed of immune organs and cells, including the spleen, thymus, lymphocytes and so on.

Lymphocytes play an important role in immune system regulation, which is an important indicator of lymphocyte activation and function. ${ }^{32}$ Splenocytes are key effector cells of the innate immune response. ${ }^{33}$ In our study, BFO-1 effectively stimulated splenocyte proliferation in vitro, in immunosuppressed mice and in S180 tumor-bearing mice. These results indicated that BFO-1 could restore the function of humoral immunity. In normal mice, BFO-1 had no significant effect on the proliferation of splenocytes. These results indicated that BFO-1 had no significant effect on humoral immunity and T cell proliferation under these experimental conditions.

Macrophages together with neutrophils represent the first line of host defense after the epithelial barrier. ${ }^{34}$ Moreover, macrophages have different cellular morphologies with different functional conditions and play a vital role in the innate immune system by increasing the secretion of inflammatory molecules, such as NO and proinflammatory molecules, to enhance the immunity. ${ }^{35}$ Recent studies have shown that most fructooligosaccharides, such as the FOS isolated from Yacon, ${ }^{36}$ FOS and inulin, ${ }^{37-39}$ could invoke the activity of immunocyte.

The production of NO can activate macrophages and stimulate immune system to protect the host from infection and tumors. ${ }^{40}$ Nonetheless, an excess of NO in the cell may damage the DNA and have a proinflammatory effect. ${ }^{41}$ In our study, BFO1 significantly increased the production of $\mathrm{NO}$ in normal mice and S180 mice, indicating that BFO-1 can enhance the innate immunity and activate the microbicidal processes inside cells. However, in normal mice, the production of NO was enhanced but did not continually increase with the increase of BFO-1 concentration. The production of NO at $1000 \mathrm{mg}$ per $\mathrm{kg}$ per day was reduced compared to the concentrations of 250 and $500 \mathrm{mg}$ per kg per day (Fig. 3A). In contrast, in S180 mice, the production of NO was concentration-dependent. This result indicates that the optimal concentration of BFO-1 required for improving immunity is different in normal and S180 mice.

The microbicidal activity in macrophages is related to a rapid and deep shift of the $\mathrm{pH}$ toward acidic values in phagolysosomes and to the action of lysozyme, hydrolytic enzymes and defensins. ${ }^{41}$ The selection of acid phosphatase and phagocytic function are important indicators of macrophages that reflect the state of cellular immunity. In this study, BFO-1 significantly increased the phagocytic function and acid phosphatase activity of peritoneal macrophages in normal mice, immunosuppressed mice and S180 mice. These results suggest that BFO can enhance the nonspecific immune and immunomodulatory effects of the body by activating macrophages.

Serum hemolysin and B-cell-mediated hemolysis demonstrate the ability of B lymphocytes to differentiate into plasma cells and produce antibodies when stimulated by antigens. In addition, B-cell mediated hemolysis reflects the number of lymphocyte antibodies, reflecting the ability of the immune system to synthesize antibodies. ${ }^{42}$ In our study, serum hemolysin levels and B-cell mediated hemolysis were used as indicators to detect humoral immunity. When observing the effect of BFO-1 on cyclophosphamide-treated immunosuppressed mice, it was found that BFO-1 had a restorative effect on cellular immunity and humoral immune function in mice. The enhancement effect of BFO-1 on immunosuppressed mice indicates that BFO-1 will be used as an auxiliary food for cyclophosphamide chemotherapy patients hopefully by improving the immune function of patients and preventing damage to the immune system.

In recent years, increasing focus has been placed on the biological activities of inulin and fructooligosaccharide especially the immunostimulatory and antitumor activities. ${ }^{\mathbf{4 3}}$ However, there are no reports on the antitumor and immunomodulatory activity of BFO-1. In our study, intragastric pretreatment with BFO-1 significantly delayed the tumor growth in S180 tumor-bearing mice (Table 2). BFO-1 also enhanced the
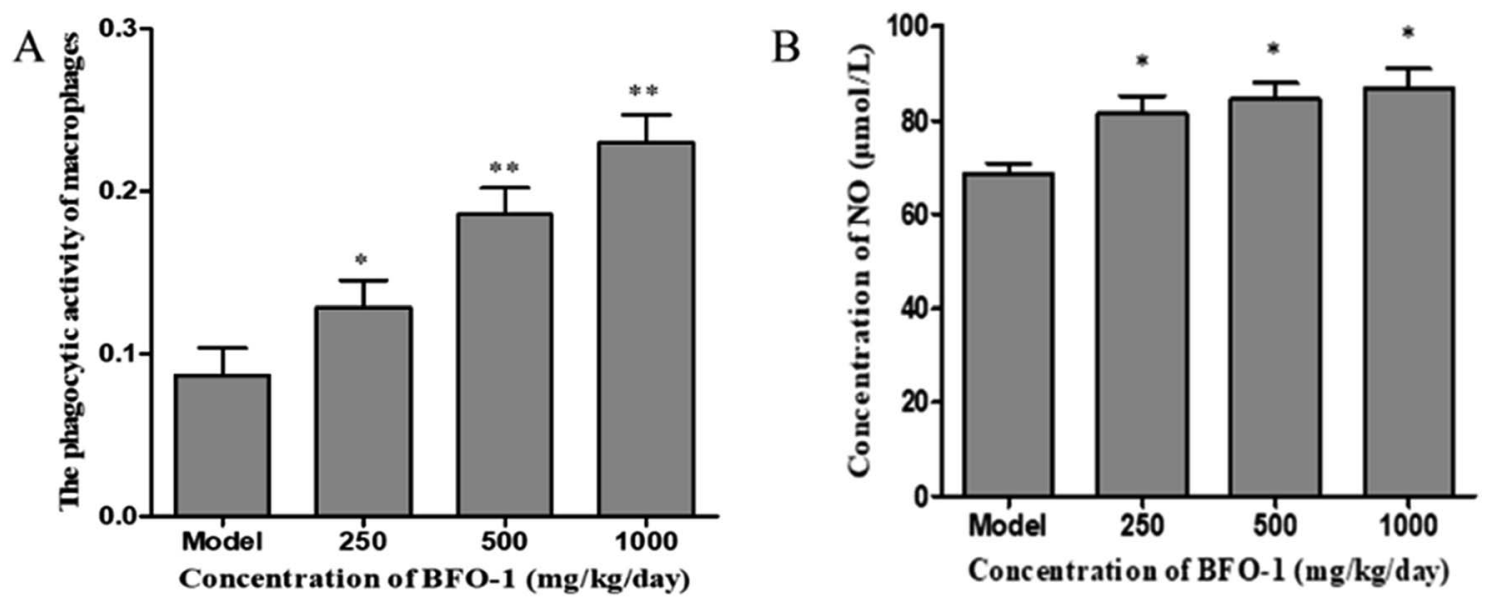

Fig. 6 Effect of BFO-1 on the activities of peritoneal macrophages in S180 tumor-bearing mice. (A) Effect of BFO-1 on phosphatase activity. (B) Effect of BFO-1 on the production of NO in macrophages. The results are expressed as the mean values \pm SD ( $n=8, * p \leq 0.05$ versus model group). 
phagocytic function of macrophages and their ability to produce NO, which should mediate macrophages killing of tumor cells. Research has shown that some immunosaccharides primed macrophages for an enhanced respiratory burst, directly stimulated NO production via induction of nitric oxide synthase, and induced macrophages to secrete both inflammatory (IL-1, IL-6, TNF-alpha, and IL-12) and antiinflammatory (IL-10) cytokines. ${ }^{\mathbf{2 9 , 4 1 , 4 3}}$ Our results demonstrate that BFO-1 possesses immunoenhancement activity. However, the mechanisms of the immunoenhancement properties of BFO-1 are not clear and require further study to support the present findings.

\section{Conclusions}

In this study, we isolated BFO from burdock roots, and the bacterial endotoxin in BFO was removed by DEAE-cellulose column chromatography. Our data show that BFO-1 stimulated the production of NO by macrophages and improved acid phosphatase activity in peritoneal macrophages in vitro. Intragastric of BFO-1 significantly increased the phagocytic function of peritoneal macrophages and the production of NO and acid phosphatase in vivo. Moreover, intragastric pretreatment with BFO-1 significantly delayed tumor growth in S180 tumorbearing mice, which confirmed that BFO-1 could promote the function of macrophages. These findings would be beneficial for the discovery of BFO-1 as a dietary supplement and functional food.

\section{Conflicts of interest}

The authors declare that they have no conflicts of interest.

\section{Acknowledgements}

This work was supported by Major Program of Shandong Province (No. 2015ZDJS04002), the Major State Basic Research Development Program of China (973 Program) (No. 2012CB822102) and the High Technology Research and Development Program of China (863 Program) (No. 2012AA021501).

\section{References}

1 T. Yang, M. Jia, J. Meng, H. Wu and Q. Mei, Int. J. Biol. Macromol., 2006, 39, 179-184.

2 L. Guo, J. Liu, Y. Hu, D. Wang, Z. Li, J. Zhang, T. Qin, X. Liu, C. Liu, X. Zhao, Y. P. Fan, G. Han and T. L. Nguyen, Carbohydr. Polym., 2012, 90, 1055-1060.

3 Y. Chen, M.-Y. Xie, S.-P. Nie, C. Li and Y.-X. Wang, Food Chem., 2008, 107, 231-241.

4 M. C. Kang, S. Y. Kim, Y. T. Kim, E. A. Kim, S. H. Lee, S. C. Ko, W. A. Wijesinghe, K. W. Samarakoon, Y. S. Kim, J. H. Cho, H. S. Jang and Y. J. Jeon, Carbohydr. Polym., 2014, 99, 365371.

5 T. M. A. Moro, C. M. Celegatti, A. P. A. Pereira, A. S. Lopes, D. F. Barbin, G. M. Pastore and M. T. P. S. Clerici, $L W T$, 2018, 90, 540-546.
6 X. Tian, S. Sui, J. Huang, J. P. Bai, T. S. Ren and Q. C. Zhao, Environ. Toxicol. Pharmacol., 2014, 38, 189-198.

7 Z. Zheng, X. Wang, P. Liu, M. Li, H. Dong and X. Qiao, Molecules, 2018, 23, 429.

8 D. Tousch, L. P. Bidel, G. Cazals, K. Ferrare, J. Leroy, M. Faucanie, H. Chevassus, M. Tournier, A. D. Lajoix and J. Azay-Milhau, J. Agric. Food Chem., 2014, 62, 7738-7745.

9 G. Lee, Y. Son, Y. Jeon, H. Kang and I. Hwang, Korean J. Food Sci. Technol., 2015, 47, 336-344.

10 W. S. Yang, S. R. Lee, Y. J. Jeong, D. W. Park, Y. M. Cho, H. M. Joo, I. Kim, Y. B. Seu, E. H. Sohn and S. C. Kang, J. Agric. Food Chem., 2016, 64, 3564-3573.

11 J. R. de Oliveira, R. B. de Aguiar Almeida, P. das Gracas Figueiredo Vilela, F. E. de Oliveira, R. F. da Rocha, A. O. Jorge and L. D. de Oliveira, Arch. Oral Biol., 2014, 59, 808-814.

12 K.-Y. Ji, J.-H. Jang, E.-H. Lee, S.-M. Kim, H.-W. Song, W.-K. Yang, H.-Y. Kim, K.-H. Kim, Y.-S. Lee, D.-S. Kim, H.-S. Kang and S.-H. Kim, J. Funct. Foods, 2018, 45, 24-33.

13 J. M. F. Rodriguez, A. R. C. de Souza, R. L. Krüger, M. C. M. Bombardelli, C. S. Machado and M. L. Corazza, J. Supercrit. Fluids, 2018, 135, 25-33.

14 R. C. Fierascu, M. I. Georgiev, I. Fierascu, C. Ungureanu, S. M. Avramescu, A. Ortan, M. I. Georgescu, A. N. Sutan, A. Zanfirescu, C. E. Dinu-Pirvu, B. S. Velescu and V. Anuta, Food Chem. Toxicol., 2018, 111, 44-52.

15 Y. Gao, C. Gu, K. Wang, H. Wang, K. Ruan, Z. Xu and Y. Feng, Phytother. Res., 2018, 32, 631-642.

16 C. H. Yen, H. F. Chiu, S. Y. Huang, Y. Y. Lu, Y. C. Han, Y. C. Shen, K. Venkatakrishnan and C. K. Wang, Helicobacter, 2018, 23, e12469.

17 F.-A. Chen, A.-B. Wu and C.-Y. Chen, Food Chem., 2004, 86, 479-484.

18 D. Li, J. M. Kim, Z. Jin and J. Zhou, Anaerobe, 2008, 14, 29-34. 19 W. S. Chung, A. W. Walker, P. Louis, J. Parkhill, J. Vermeiren, D. Bosscher, S. H. Duncan and H. J. Flint, BMC Biol., 2016, 14,3 .

20 B. Mao, D. Li, J. Zhao, X. Liu, Z. Gu, Y. Q. Chen, H. Zhang and W. Chen, J. Agric. Food Chem., 2015, 63, 856-863.

21 C. J. Zheng, R. Liu, B. Xue, J. Luo, L. Gao, Y. Wang, S. Ou, S. Li and X. Peng, Food Funct., 2017, 8, 1925-1932.

22 G. Flamm, W. Glinsmann, D. Kritchevsky, L. Prosky and M. Roberfroid, Crit. Rev. Food Sci. Nutr., 2001, 41, 353-362.

23 S. A. Kumar, L. C. Ward and L. Brown, Br. J. Nutr., 2016, 116, 1502-1511.

24 P. D. Schley and C. J. Field, Br. J. Nutr., 2007, 87, S221.

25 M. Roberfroid, G. R. Gibson, L. Hoyles, A. L. McCartney, R. Rastall, I. Rowland, D. Wolvers, B. Watzl, H. Szajewska, B. Stahl, F. Guarner, F. Respondek, K. Whelan, V. Coxam, M. J. Davicco, L. Leotoing, Y. Wittrant, N. M. Delzenne, P. D. Cani, A. M. Neyrinck and A. Meheust, Br. J. Nutr., 2010, 104(suppl 2), S1-S63.

26 B. van Duuren-Stuurman, M. Grollers-Mulderij, A. van de Runstraat, A. Duisterwinkel, J. Terwoert and S. Spaan, Ann. Work Exposures Health, 2018, 62, 157-166.

27 P. Prasad, S. Sachan, S. Suman, G. Swayambhu and S. Gupta, Langmuir, 2018, 34, 7396-7403. 
28 J. Tu, H. X. Sun and Y. P. Ye, J. Ethnopharmacol., 2008, 119, 266-271.

29 Z. Cai, W. Li, H. Wang, W. Yan, Y. Zhou, G. Wang, J. Cui and F. Wang, Int. J. Biol. Macromol., 2012, 51, 484-488.

30 G. Pang, J. Xie, Q. Chen and Z. Hu, Food Sci. Hum. Wellness, 2012, 1, 26-60.

31 H. Kim, K.-W. Yu, H.-D. Hong and K.-S. Shin, J. Funct. Foods, 2017, 35, 384-390.

32 S. M. Poznanski, N. G. Barra, A. A. Ashkar, J. D. Schertzer, et al., Inflammation Res., 2018, 67, 813-828.

33 Z. Yu, M. Kong, P. Zhang, Q. Sun and K. Chen, Carbohydr. Polym., 2016, 148, 318-325.

34 L. Bai, L. Y. Zhu, B. S. Yang, L. J. Shi, Y. Liu, A. M. Jiang, L. L. Zhao, G. Song and T. F. Liu, Int. J. Biol. Macromol., 2012, 51, 705-709.

35 I. A. Schepetkin and M. T. Quinn, Int. Immunopharmacol., 2006, 6, 317-333.
36 L. L. R. Paredes, F. R. Smiderle, A. P. Santana-Filho, A. Kimura, M. Iacomini and G. L. Sassaki, Int. J. Biol. Macromol., 2018, 108, 1074-1081.

37 Y. Bai, P. Zhang, G. Chen, J. Cao, T. Huang and K. Chen, Int. Immunopharmacol., 2012, 12, 611-617.

38 Z. Wei, G. Chen, P. Zhang, L. Zhu, L. Zhang and K. Chen, Carbohydr. Polym., 2018, 198, 302-312.

39 H. Kim, B. S. Kwak, H. D. Hong, H. J. Suh and K. S. Shin, Int. J. Biol. Macromol., 2016, 87, 308-316.

40 M. A. Rahat and B. Hemmerlein, Front Physiol., 2013, 4, 144.

41 I. V. Yegorenkova, A. A. Fomina, K. V. Tregubova, S. A. Konnova and V. V. Ignatov, Arch. Microbiol., 2018, 200, 1471-1480.

42 S. Saravanan, N. Prakash Babu, P. Pandikumar, M. Karunai Raj, M. Gabriel Paulraj and S. Ignacimuthu, J. Ethnopharmacol., 2012, 140, 239-246.

43 A. Nawaz, A. Bakhsh Javaid, S. Irshad, S. H. Hoseinifar and H. Xiong, Fish Shellfish Immunol., 2018, 76, 272-278. 